\title{
Relationship between tumour endothelial cell apoptosis and tumour blood flow shutdown following treatment with the antivascular agent DMXAA in mice
}

\author{
L-M Ching ', ', S Zwain' and BC Baguley' \\ 'Auckland Cancer Society Research Centre, Faculty of Medical and Health Sciences, The University of Auckland, Private Bag 92019, Auckland, \\ New Zealand
}

5,6-Dimethylxanthenone-4-acetic acid (DMXAA) is currently undergoing clinical evaluation as an antivascular agent for the treatment of cancer. We have previously demonstrated that DMXAA induces apoptosis of vascular endothelial cells in murine tumour sections and in a breast carcinoma biopsy from one patient in a Phase I trial. We wished to determine the tissue selectivity of this effect and its relationship to induced blood flow changes. Mice with Colon 38 tumours were treated with DMXAA and tissues were examined for apoptosis by TdT-mediated dUTP nick-end labelling (TUNEL). Hoechst 33342 was used to stain functional vessels, with the loss of stained vessels used as a measure of tumour vascular collapse. Treatment with DMXAA at $25 \mathrm{mg} \mathrm{kg}^{-1}$, its maximum tolerated dose (MTD), showed, after $3 \mathrm{~h}$, a I2-fold increase in TUNEL staining of tumour vascular endothelial cells. In contrast, tissue from the heart, brain, liver and spleen showed no increase. Induction of apoptosis in tumour tissue was both dose-dependent, observable at doses as low as $5 \mathrm{mg} \mathrm{kg}^{-1}$, and time-dependent. Apoptosis was significantly lower in Colon 38 tumours of mice, with a targeted disruption in the TNF gene $\left(\mathrm{TNF}^{--}\right)$, or in the TNF receptor I gene $\left(\mathrm{TNFR}^{--}\right)$, as compared with that in wild-type mice. Increasing the DMXAA dose to $50 \mathrm{mg} \mathrm{kg}^{-1}$ in these knockout mice raised tumour apoptosis to a level comparable to that induced in wild-type mice given DMXAA at the MTD. For all the data, a significant correlation $(r=0.94 ; P<0.00 \mathrm{I})$ was found between logarithmic percentage apoptosis induction and the logarithmic density of Hoechst-stained vessels. These results suggest that blood flow inhibition caused by DMXAA is tumour tissue-specific and is a consequence of induction of apoptosis in tumour vascular endothelial cells.

British Journal of Cancer (2004) 90, 906 -910. doi:I0.1038/sj.bjc.660 I606 www.bjcancer.com

(C) 2004 Cancer Research UK

Keywords: antivascular; blood flow; Hoechst 33342; knockout mice; tumour necrosis factor; apoptosis

5,6-dimethylxanthenone-4-acetic acid (DMXAA), a new anticancer agent synthesised in this laboratory (Rewcastle et al, 1991), is currently undergoing clinical evaluation as an antivascular agent for the treatment of cancer. In mice with transplantable tumours, DMXAA caused cessation of tumour blood flow, vascular collapse and tumour necrosis (Rewcastle et al, 1991; Zwi et al, 1994; Lash et al, 1998). DMXAA also increased tumour necrosis factor (TNF) concentrations in both plasma and tumour tissue of mice (Philpott et al, 1995; Ching et al, 1999). We have previously used TdTmediated dUTP nick-end labelling (TUNEL) assays to demonstrate the induction of apoptosis of the vascular endothelium in Colon 38 tumours in mice treated with DMXAA at its optimal dose (Ching et al, 2002). Staining was detectable within $30 \mathrm{~min}$ of administration, intensified with time, and necrosis of adjacent tumour tissue was evident after $3 \mathrm{~h}$. Some apoptosis of splenic tissue was detected in tumour-bearing mice, but none was observed in the liver tissue. Of particular interest was the finding of TUNEL staining of tumour vascular endothelium in breast tumour biopsies taken from a patient 3 and $24 \mathrm{~h}$ after infusion of DMXAA $\left(3100 \mathrm{mg} \mathrm{m}^{-2}\right)$ in a Phase I clinical trial. Thus, DMXAA is capable of inducing apoptosis in vascular endothelial cells in both mice and human tumours.

*Correspondence: Dr L-M Ching; E-mail: I.ching@auckland.ac.nz Received 22 September 2003; accepted 27 October 2003
The finding of a rapid onset of tumour endothelial apoptosis, occurring before the appearance of detectable TNF in tumour tissue (Ching et al, 1999), suggests that DMXAA exerts a direct effect on tumour vasculature, and is of particular relevance to clinical trials. In this report, we have used in vivo vascular labelling techniques to investigate the relationship between apoptosis induction and tumour blood flow reduction. To investigate the role of TNF, we utilised mice with a targeted disruption of the TNF gene $\left(\mathrm{TNF}^{-I-}\right)$ or of the TNF receptor 1 gene $\left(\mathrm{TNFR}^{-I-}\right)$.

\section{MATERIALS AND METHODS}

\section{Materials}

DMXAA was synthesised at the Auckland Cancer Society Research Centre (Rewcastle et al, 1991) and dissolved in minimal 5\% sodium bicarbonate for intraperitoneal injection into mice $\left(25 \mathrm{mg} \mathrm{kg}^{-1}\right)$ in a volume of $0.01 \mathrm{ml} \mathrm{g}^{-1}$ body weight. Hoechst 33342 (Sigma Chemical Co., St Louis, MO, USA) was dissolved at $8 \mathrm{mg} \mathrm{ml}^{-1}$ in saline and stored at $-80^{\circ} \mathrm{C}$.

\section{Mice}

All mice were housed and used under institutional, ethical guidelines. All animal experiments have been carried out with 
ethical committee approval. The ethical guidelines that were followed meet the standards required by the UKCCCR guidelines (Workman et al, 1998). C57Bl/6 mice were obtained from the Animal Resource Unit, University of Auckland. $\mathrm{TNF}^{-1-}$ and $\mathrm{TNFR}^{-1-}$ knockout mice on a C57Bl/6 background were offspring from breeding pairs obtained, respectively, from the Centenary Institute, Sydney, Australia, and Jackson Laboratory, Bar Harbor, ME, USA. Colon 38 tumour fragments $\left(1 \mathrm{~mm}^{3}\right)$ were implanted subcutaneously in the left flank of anaesthetised $\left(82 \mathrm{mg} \mathrm{kg}^{-1}\right.$ sodium pentobarbitone) mice. Tumours were used when they had reached approximately $6 \mathrm{~mm}$ in diameter, generally 10 days after implantation. At least three mice were assigned for each group.

\section{Histochemistry}

Apoptosis was determined using the TUNEL assay for the identification of double-stranded DNA breaks using the In situ Cell Death Detection Kit (Roche Diagnostics, Mannheim, Germany), according to the manufacturer's instructions. Tissue cryosections (14 $\mu \mathrm{m}$ thickness) on poly-L-lysine-coated slides were fixed in $4 \%$ paraformaldehyde in phosphate-buffered saline (PBS) for $30 \mathrm{~min}$ at room temperature, washed three times with PBS for 10 min each time, dehydrated for $2 \mathrm{~min}$ in absolute ethanol and then treated with permeabilisation solution (1\% Triton X-100 in $1 \%$ sodium citrate) for 15 min at room temperature. Strand breaks were labelled with fluoresceinated dUTP and visualised following reaction with either antifluorescein antibody conjugated with alkaline phosphatase and Vector ${ }^{\circledR}$ Black alkaline phosphatase substrate solution (Vector Laboratories, Burlingame, CA, USA) or antifluorescein antibody conjugated with horseradish peroxidase (POD) and diaminobenzidine (DAB) substrate (Roche Diagnostics, Mannheim, Germany). All slides were counter stained using methyl green. The amount of apoptotic staining in the sections was quantitated using Adobe Photoshop, Version 4 (Adobe
Systems Inc., San Jose, CA, USA). For each of 5-10 random fields of tumour sections (2-3 tumours per group), the number of pixels stained with TUNEL was determined, divided by the total number of pixels, and expressed as a percentage.

Tissue cryosections were also fixed in cold acetone for $20 \mathrm{~min}$ at $4^{\circ} \mathrm{C}$, blocked with $1.5 \%$ normal rabbit serum for $1 \mathrm{~h}$ at room temperature, incubated with avidin-biotin for $15 \mathrm{~min}$, and then incubated with 1:100 dilution of rat anti-mouse CD-31 monoclonal antibody (MEC 13.3; BD Pharmingen, USA) overnight at $4{ }^{\circ} \mathrm{C}$ in a humidified container. Sections were then incubated with $1: 100$ dilution of biotinylated anti-rat IgG antibody and avidinbiotin complex (Vectastain ABC-AP Kit, Vector Laboratories, Burlingame, CA, USA). Immunoglobulin complexes were visualised using Vector Red alkaline phosphatase substrate solution, also from Vector Laboratories.

\section{Hoechst 33342 staining of functional vessels}

Hoechst $33342\left(8 \mathrm{mg} \mathrm{ml}^{-1}\right.$ in saline) was injected via the tail vein at $0.1 \mathrm{ml}$ per mouse $3 \mathrm{~h}$ after DMXAA treatment. Mice were killed 2 min later by cervical dislocation and the tumours were excised and frozen at $-80^{\circ} \mathrm{C}$. Cryosections $(14 \mu \mathrm{m})$ of the tumour were examined using a fluorescence microscope with a UV-1A filter block (excitation $365 \mathrm{~nm}$, barrier filter $400 \mathrm{~nm}$, dichroic mirror $400 \mathrm{~nm}$ ). Five -10 fields per tumour were scored (two to three tumours per group), and the number of positively stained vessels per $1 \mathrm{~mm}^{-2}$ field was calculated.

\section{Statistical analyses}

Data were analysed using a paired Student's $t$-test and by standard correlation analysis. A probability value of $<0.05$ was considered significant.
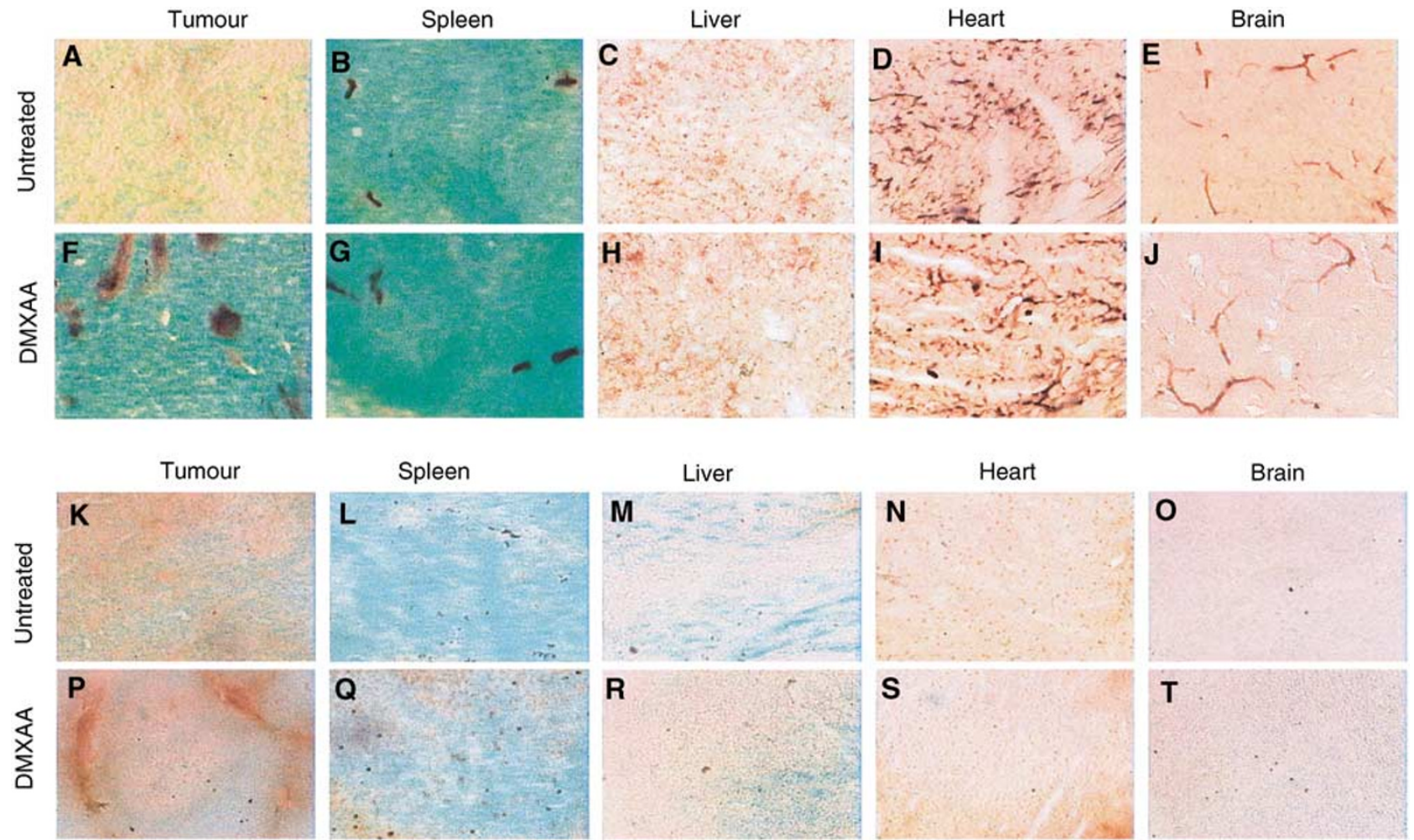

Figure I Selective induction of tumour vascular endothelial cell apoptosis by DMXAA. Sections from Colon 38 tumours, spleen, liver, heart and brain from untreated or treated (DMXAA, $\left.25 \mathrm{mg} \mathrm{kg}^{-1}, 3 \mathrm{~h}\right)$ C57B//6 mice were stained for TUNEL with alkaline phosphatase substrate $(\mathbf{A}-\mathbf{J})$ or POD/DAB $(\mathbf{K}-\mathbf{T})$. Stained sections shown at $\times 100$ magnification. 


\section{RESULTS}

\section{Endothelial cell apoptosis in various tissues following DMXAA}

Sections of Colon 38 tumours, liver, spleen, heart and brain collected from $\mathrm{C} 57 \mathrm{Bl} / 6$ mice without treatment or $3 \mathrm{~h}$ after DMXAA administration $\left(25 \mathrm{mg} \mathrm{kg}^{-1}\right)$ were stained for apoptosis using TUNEL (Figure 1). Tumour sections from DMXAA-treated mice showed 12.5- and 12-fold increases in apoptosis staining over that in tumour sections from untreated mice using alkaline phosphatase, or POD/DAB, respectively, as the enzyme system for visualisation of apoptosis staining (Figure 2). No statistically significant increases in apoptosis staining were observed in other tissues (Figure 2). Liver sections from treated or untreated mice showed no staining. Using alkaline phosphatase, false-positive background staining was observed in the spleen, heart and brain sections of tumour-bearing and nontumour-bearing mice, and in negative control sections that had not been incubated with the immunohistochemistry reagents. Staining of sections of brain, liver, heart or spleen from treated or untreated mouse was not observed using the DAB substrate system, which confirmed that induction of apoptosis following DMXAA treatment was specific to

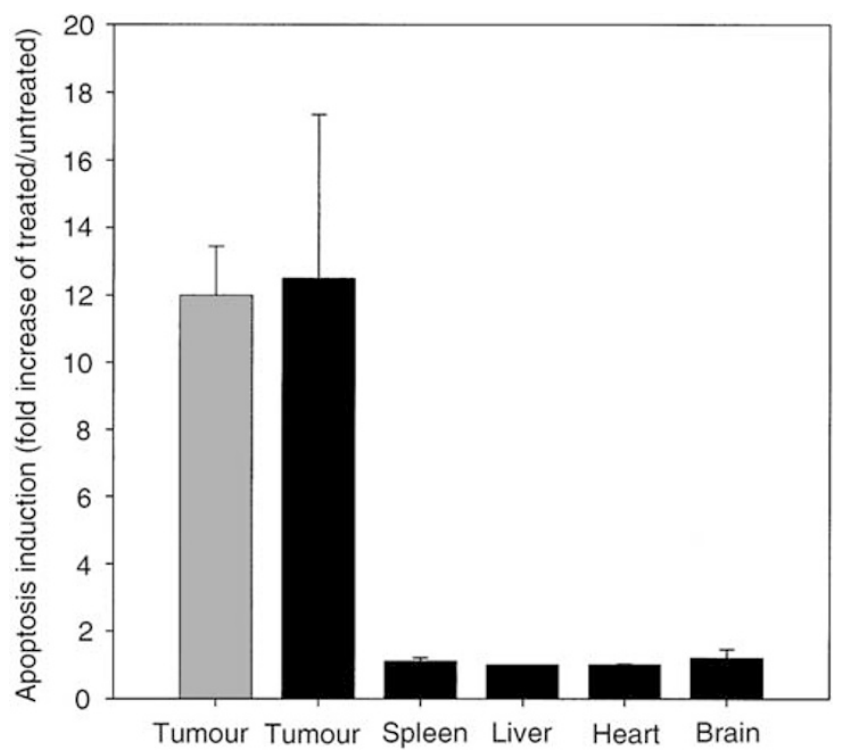

Figure 2 Apoptosis after $3 \mathrm{~h}$ in Colon 38 tumours, spleen, liver, heart and brain from mice treated with $25 \mathrm{mg} \mathrm{kg}^{-1}$ DMXAA. Bars represent ratios of percentage TUNEL-stained areas in the treated tissue to that in untreated tissue. Alkaline phosphatase substrate (black bars); POD/DAB substrate (grey bars). tumour tissue (Figure 1). Similar ratios of apoptosis induction in tumour tissues were obtained using either POD/DAB or alkaline phosphatase (Figure 2), but the latter produced more intense labelling and was used in subsequent studies with tumour tissues.

To ascertain whether the apoptotic cells were endothelial cells, adjacent cryosections were stained with antibodies to CD-31 and the pattern of staining with the anti-CD-31 and apoptosis compared. Similar staining patterns were observed, providing strong evidence for DMXAA-induced endothelial apoptosis.

Dose-response relationship and time course of DMXAAinduced tumour endothelial cell apoptosis and blood flow inhibition

A significant increase in apoptotic vessels in Colon 38 tumour sections, analysed $3 \mathrm{~h}$ after DMXAA treatment, was seen at doses as low as $5 \mathrm{mg} \mathrm{kg}^{-1}$ (Table 1, Figure 3A). The frequency of apoptotic vessels increased with increasing dose, with a particularly sharp increase from $20 \mathrm{mg} \mathrm{kg}^{-1}$ (six-fold induction as compared to untreated controls) to the MTD of $25 \mathrm{mg} \mathrm{kg}^{-1}$ (12.5-fold induction; Table 1). Apoptosis of tumour vascular endothelial cells was detectable as early as $15 \mathrm{~min}$ (2.5-fold increase) and progressively increased with time following administration of DMXAA at the MTD (Table 1, Figure 3B).

As a measure of blood flow inhibition following DMXAA treatment, we used the perfusion marker Hoechst 33342 to stain functional vessels (Zwi et al, 1989). No inhibition of blood flow was observed after $3 \mathrm{~h}$ with DMXAA doses of 5 and $10 \mathrm{mg} \mathrm{kg}^{-1}$. Inhibition was $56 \%$ at a dose of $15 \mathrm{mg} \mathrm{kg}^{-1}$ and increased progressively with dose up to the MTD (Table 1, Figure 3A). Blood flow was significantly reduced (39\%) 30 min after DMXAA treatment at $25 \mathrm{mg} \mathrm{kg}^{-1}$, and reached $76 \%$ inhibition after $3 \mathrm{~h}$ (Table 1, Figure 3B).

\section{DMXAA-induced tumour endothelial cell apoptosis and blood flow shutdown in $\mathrm{TNF}^{-l-}$ and $\mathrm{TNFR}^{-I-}$ mice}

To determine if the antivascular effects of DMXAA were TNFdependent, we compared the responses in $\mathrm{TNF}^{-1-}$ and $\mathrm{TNFR}^{-1-}$ mice to those in wild-type $\mathrm{C} 57 \mathrm{Bl} / 6$ mice. Tumour endothelial cell apoptosis in $\mathrm{TNF}^{-1-}$ and $\mathrm{TNFR}^{-1-}$ hosts following DMXAA $\left(25 \mathrm{mg} \mathrm{kg}^{-1}\right)$ was, respectively, 1.8 - and 10.4-fold lower than that in wild-type mice. However, the knockout mice tolerated higher doses of DMXAA and, at a dose of $50 \mathrm{mg} \mathrm{kg}^{-1}$, the induced apoptosis was comparable to that obtained in wild-type mice at $25 \mathrm{mg} \mathrm{kg}^{-1}$ of DMXAA in wild-type mice. Blood flow in tumours implanted in $\mathrm{TNF}^{-1-}$ and $\mathrm{TNFR}^{-1-}$ mice was determined from Hoechst-stained vessels, and was, respectively, 2.5- and 5.3-fold lower than that in tumours in wild-type mice, $3 \mathrm{~h}$ following DMXAA at $25 \mathrm{mg} \mathrm{kg}^{-1}$. Again, however, at the higher dose of

Table I Apoptosis induction and blood flow inhibition in Colon 38 tumours following DMXAA treatment

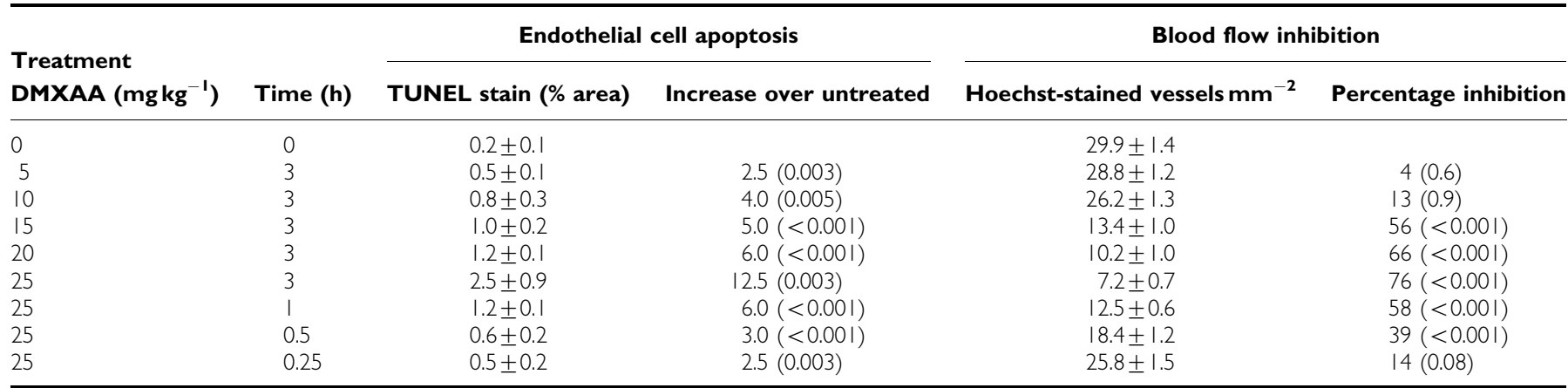

DMXAA =5,6-dimethylxanthenone-4-acetic acid. P-values in brackets represent the degree of statistical difference between treated and untreated controls. 
$50 \mathrm{mg} \mathrm{kg}^{-1}$, which can be tolerated by the knockout mice, inhibition of blood flow was similar to that obtained at $25 \mathrm{mg} \mathrm{kg}^{-1}$ in wild-type mice (Table 2).

\section{DISCUSSION}

These results confirm our previous findings (Ching et al, 2002) that DMXAA induces endothelial cell apoptosis in Colon 38 tumours. Apoptosis induction was selective to tumour vascular
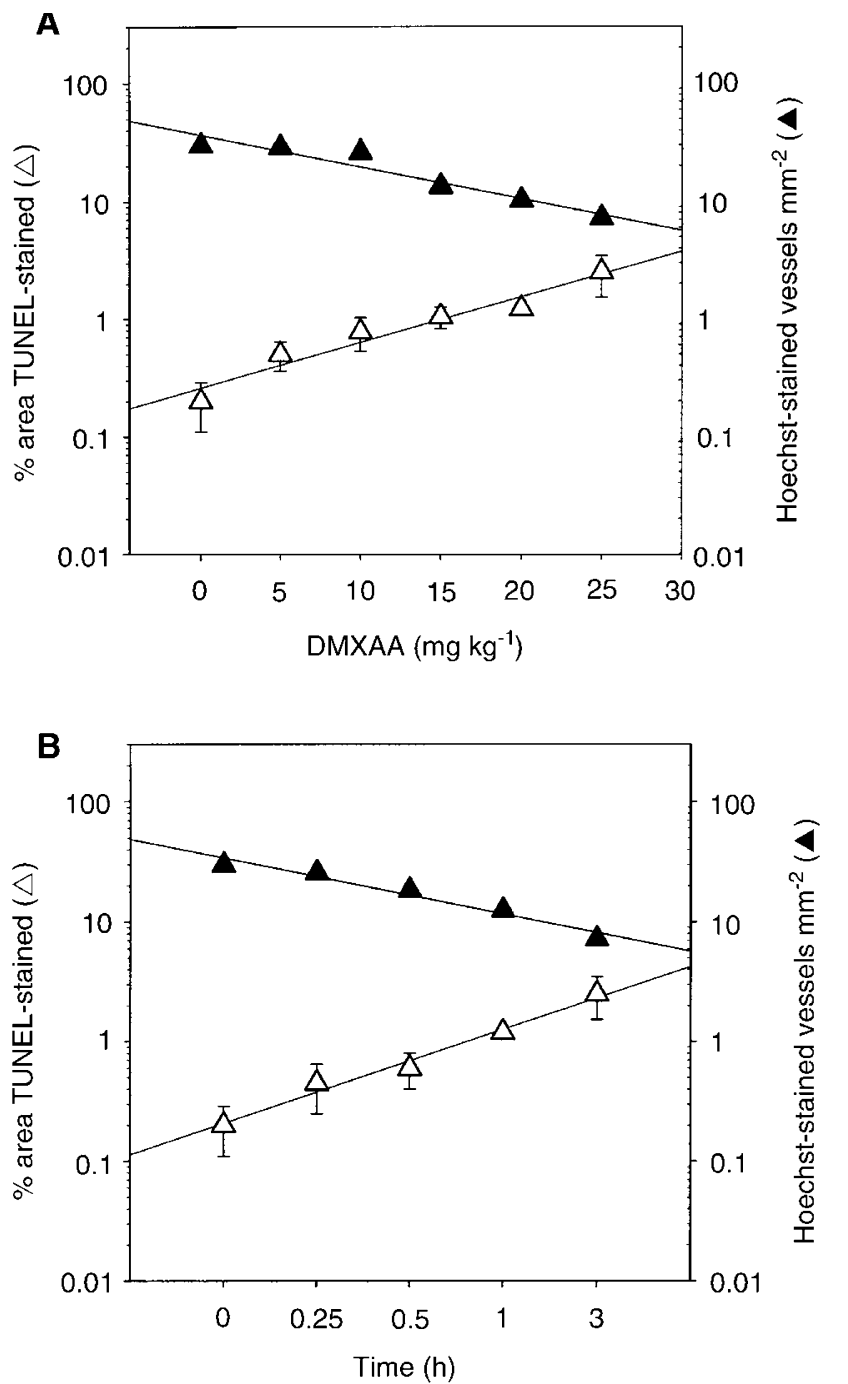

Figure 3 Apoptosis and blood flow measured in Colon 38 tumours treatment with DMXAA at different doses after $3 \mathrm{~h}(\mathbf{A})$, or at different times after DMXAA at a dose of $25 \mathrm{mg} \mathrm{kg}^{-1}(\mathbf{B})$. Percentage TUNELstained areas $(\Delta)$; Hoechst-stained vessels $\mathrm{mm}^{-2}(\boldsymbol{\Lambda})$. endothelium and was not seen in liver, heart, brain or spleen (Figures 1 and 2). We had previously reported apoptosis staining in splenic tissues, using alkaline phosphatase for the detection of the bound antibodies (Ching et al, 2002), but the results here show that the staining observed in the normal organs using the alkaline phosphatase procedure was not DMXAA-induced and was likely to be due to high endogenous phosphatase levels that had not been completely blocked (Figure 2). The basis for the pronounced selectivity for tumour vasculature is not yet understood. Factors secreted by tumour-associated immune cells, or by the tumour cells themselves, may play a role by 'priming' the response of tumour endothelial cells to DMXAA. Tumour-conditioned medium has been reported to play a role in modulating the response of cultured endothelial cells to flavone acetic acid (Watts and Woodcock, 1992). Endothelial cells in culture are resistant to apoptosis induction by DMXAA (Ching et al, 2002), and we have found that addition of serum from Colon 38-bearing mice did not render them sensitive (unpublished results).

To determine whether there was a relationship between the degree of blood flow inhibition and endothelial cell apoptosis induction, all the data for both wild-type and knockout mice treated with DMXAA with different doses and at different times were plotted on the same graph (Figure 4). A highly significant logarithmic relationship was found $(r=0.94 ; P<0.001)$, indicating that a $10 \%$ increase in apoptosis leads to a $7 \%$ decrease in blood flow. The degree of significance suggests that tumour blood flow inhibition is a consequence of endothelial cell apoptosis. Damage

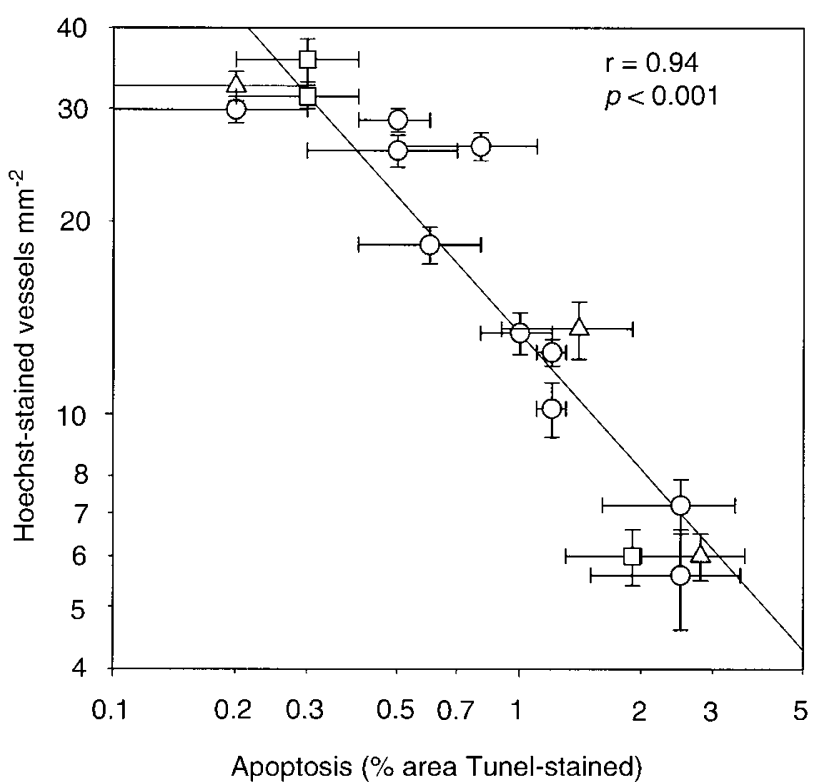

Figure 4 Relationship between the logarithm of induced apoptosis and the logarithm of blood flow inhibition in Colon 38 tumours, plotted for all the experiments. Wild-type C57BI/6 (O); $\operatorname{TNF}^{-1-}(\Delta)$; $\operatorname{TNFR}^{-1-}(\square)$.

Table 2 Endothelial cell apoptosis and blood flow inhibition in tumours from C57BI/6, $\mathrm{TNF}^{-1-}$ and TNFR ${ }^{-1-}$ mice following DMXAA treatment

\begin{tabular}{|c|c|c|c|c|c|c|}
\hline \multirow[b]{2}{*}{ DMXAA } & \multicolumn{3}{|c|}{ Percentage TUNEL-stained areas } & \multicolumn{3}{|c|}{ Hoechst-stained vessels $\mathrm{mm}^{-2}$} \\
\hline & C57B $1 / 6$ & $\mathbf{T N F}^{-1-}$ & TNFR $^{-I-}$ & C57BI/6 & $\mathbf{T N F}^{-1-}$ & TNFR $^{-1-}$ \\
\hline
\end{tabular}

DMXAA = 5,6-dimethylxanthenone-4-acetic acid. 
to the endothelium and subsequent loss of the structural integrity of the vessels leading to increase in vascular permeability would result in a reduction in blood flow (Baguley, 2003).

TNF is induced following DMXAA administration to mice (Philpott et al, 1995), and the histology of tumours treated with DMXAA resembles that of TNF-treated tumours, suggesting that TNF participates in the antivascular action. Support for this hypothesis is provided by experiments where Colon 38 tumours were implanted in $\mathrm{TNF}^{-1-}$ and $\mathrm{TNFR}^{-1-}$ knockout mice, where the antitumour effects following administration of the same dose of DMXAA are substantially reduced (Ching et al, 1999; Zhao et al, 2002). In agreement with these findings, apoptosis induction and tumour blood flow inhibition following treatment with DMXAA $\left(25 \mathrm{mg} \mathrm{kg}^{-1}\right)$ were pronounced in tumours implanted in wild-type mice, but small in tumours implanted in $\mathrm{TNF}^{-1-}$ and $\mathrm{TNFR}^{-1-}$ knockout mice (Table 2). The lower toxicity of DMXAA in these knockout mice allows the use of higher drug doses, which restored both apoptosis induction and tumour blood flow inhibition

\section{REFERENCES}

Baguley BC (2003) Antivascular therapy of cancer: DMXAA. Lancet Oncol 4: $141-148$

Ching L-M, Cao Z, Kieda C, Zwain S, Jameson MB, Baguley BC (2002) Induction of endothelial cell apoptosis by the antivascular agent 5,6dimethylxanthenone-4-acetic acid. Br J Cancer 86: 1937-1942

Ching LM, Goldsmith D, Joseph WR, Korner H, Sedgwick JD, Baguley BC (1999) Induction of intratumoral tumor necrosis factor (TNF) synthesis and hemorrhagic necrosis by 5,6-dimethylxanthenone-4-acetic acid (DMXAA) in TNF knockout mice. Cancer Res 59: 3304-3307

Jameson MB, Thompson PI, Baguley BC, Evans BD, Harvey VJ, Porter DJ, McCrystal MR, Small M, Bellenger K, Gumbrell L, Halbert GW, Kestell P (2003) Phase I trial of the antivascular agent 5,6-dimethylxanthenone-4acetic acid (DMXAA). Br J Cancer 88: 1844-1850

Lash CJ, Li AE, Rutland M, Baguley BC, Zwi LJ, Wilson WR (1998) Enhancement of the anti-tumour effects of the antivascular agent 5,6dimethylxanthenone-4-acetic acid (DMXAA) by combination with 5hydroxytryptamine and bioreductive drugs. Br J Cancer 78: 439-445

Philpott M, Baguley BC, Ching L-M (1995) Induction of tumour necrosis factor-alpha by single and repeated doses of the antitumour agent 5,6dimethylxanthenone-4-acetic acid. Cancer Chemother Pharmacol 36: $143-148$

Rewcastle GW, Atwell GJ, Zhuang L, Baguley BC, Denny WA (1991) Potential antitumor agents. 61. Structure-activity relationships for in responses. The results are consistent with the hypothesis that DMXAA can exert an antivascular response both directly and indirectly by induction of TNF, and perhaps of other cytokines. The relationship in Figure 4 suggests that both direct and indirect mechanisms act with a similar relationship between apoptosis induction and tumour blood flow inhibition. These results are of particular importance to clinical studies, since TNF levels were not found to be raised in Phase I clinical trials of DMXAA but tumour blood flow shutdown at doses above $500 \mathrm{mg} \mathrm{m}^{-2}$ was clearly demonstrable (Rustin et al, 1998; Jameson et al, 2003). Multiple mediators of antivascular effects may be involved in providing a selective antitumour effect.

\section{ACKNOWLEDGEMENT}

This work was supported by the Auckland Cancer Society. vivo colon 38 activity among disubstituted 9-oxo-9H-xanthene-4-acetic acids. J Med Chem 34: 217-222

Rustin G, Galbraith S, Taylor N, Stratford M, Bradley C, Thompson P, Jameson M, Baguley B (1998) Impact on tumour perfusion measured by dynamic magnetic resonance imaging (MRI), in the phase 1 trial of 5,6dimethylxanthenone-4-acetic acid (DMXAA). Ann Oncol 9: 126

Watts ME, Woodcock M (1992) Flavone acetic acid induced changes in human endothelial permeability - potentiation by tumour-conditioned medium. Eur J Cancer 28A: 1628-1632

Workman P, Twentyman P, Balkwill F, Balmain A, Chaplin D, Double J, Embleton J, Newell D, Raymond R, Stables J, Stephens T, Wallace J (1998) United Kingdom Co-ordinating Committee on Cancer Research (UKCCCR) guidelines for the welfare of animals in experimental neoplasia (second edition). Br J Cancer 77: 1 - 10

Zhao L, Ching LM, Kestell P, Baguley BC (2002) The antitumour activity of 5,6-dimethylxanthenone-4-acetic acid (DMXAA) in TNF receptor-1 knockout mice. $\mathrm{Br}$ J Cancer 87: $465-470$

Zwi LJ, Baguley BC, Gavin JB, Wilson WR (1989) Blood flow failure as a major determinant in the antitumor action of flavone acetic acid (NSC 347512). J Natl Cancer Inst 81: $1005-1013$

Zwi LJ, Baguley BC, Gavin JB, Wilson WR (1994) Correlation between immune and vascular activities of xanthenone acetic acid antitumor agents. Oncol Res 6: 79-85 